\title{
In Vitro and in Silico Assessment of the Potential of Niaouli Essential Oil as a Quorum Sensing Inhibitor of Biofilm Formation and its Effects on Fibroblast Cell Viability
}

\section{Ebru Onem ${ }^{1}$}

https://orcid.org/0000-0002-7770-7958

Ahu Soyocak ${ }^{2}$

https://orcid.org/0000-0003-0999-2774

Muhammed Tilahun Muhammed ${ }^{3}$

https://orcid.org/0000-0003-0050-5271

Ayse $\mathbf{A k}^{4 *}$

https://orcid.org/0000-0002-1385-5847

${ }^{1}$ Suleyman Demirel University, Pharmaceutical Microbiology, Isparta, Turkey; ${ }^{2}$ Istanbul Aydin University, Medical Biology, Istanbul, Turkey; ${ }^{3}$ Suleyman Demirel University, Pharmaceutical Chemistry, Isparta, Turkey; ${ }^{4}$ Kocaeli University, Medical Imaging Techniques, Kocaeli, Turkey.

Editor-in-Chief: Alexandre Rasi Aoki

Associate Editor: Jane Manfron Budel

Received: 2020.12.13; Accepted: 2021.09.27.

${ }^{*}$ Correspondence: ayse.ak@kocaeli.edu.tr; (A.A.).

\section{HIGHLIGHTS}

- Essential oil (EO) of Niaouli is an inhibitor on biofilm formation of $P$. aeruginosa.

- The main components of Niaouli EO act as possible inhibitors of LasR.

- The inhibition effect of these molecules on LasR is verified by molecular docking.

- Niaouli EO has effects on cell viability of fibroblast cells at high concentrations.

- Niaouli is a valuable essential oil for pharmaceutical applications.

Abstract: Essential oils (EO), as new bioactive compounds, have been used for pharmaceutical applications. In this study, EO of Niaouli was found to have a high content in 1,8-cineole (58.53\%). Furthermore, pinene, a-terpineol, nerolidol and ledene were found to be its components with an abundance of above $2 \%$. Niaouli EO also had effects as inhibitor of Pseudomonas aeruginosa PAO1 biofilm formation $(\mathrm{p}<0.05)$. In the molecular docking study, this effect was explored. The natural ligand OdDHL, the bound ligand TP-1 (Triphenyl-1), the major component 1,8-cineole and the other components with significant abundance were docked against the binding region of the LasR protein. The docking study exhibited that 1,8-cineole together with the other components investigated could inhibit LasR competitively. Its effect on cell viability was also 
analyzed by MTT assay. Although dose-dependent cell viability effect was observed for all hours $(p<0.05)$, $\mathrm{IC}_{50}$ value was above $100 \mu \mathrm{g} / \mathrm{mL}$. Therefore, Niaouli can be assessed safely for dermatological applications because of its low toxicity on fibroblast cells and may be considered as potential quorum sensing inhibitor because of its inhibition effect on biofilm formation.

Keywords: Biofilm; fibroblast; molecular docking; niaouli; viability.

\section{INTRODUCTION}

Plant-derived compounds are very precious sources for the discovery of potent bioactive molecules that are potential drugs [1-3]. Compounds of medicinal plants, especially essential oils (EOs), have been used for their antioxidative, anti-inflammatory and antibacterial properties [3]. Biological activity of EOs mainly depends on their chemical composition and purpose of usage. EOs, which are used for aromatherapy, are considered to have low toxicity and good bioavailability $[4,5]$. EO of Niaouli may be used for aromatherapy and is extracted from leaves of Melaleuca viridiflora. It has high level of monoterpenes and sesquiterpenes, the main terpene component being 1,8-cineole [6]. Niaouli EO has antiviral, antiseptic and antibacterial activities $[7,8]$.

An organism capable of forming a biofilm has advantages such as protection from antibiotics, disinfectants and changing conditions. In the public health sector, the colonization of catheter and implanted device surfaces by biofilms play a decisive role in the problem of healthcare-associated infections $[9,10]$. Pseudomonas aeruginosa has high tolerance to antibiotics by forming biofilm, and it has been reported that the expression of the efflux pump is more active in biofilm-associated cells than planktonic cells $[11,12]$. The release of virulence factors, which have an important role in the occurrence of $P$. aeruginosa PAO1-induced infectious diseases, takes place under the control of the system called the quorum sensing system (QS). $P$. aeruginosa produces $N$-Acylated L-Homoserine lactone (AHL), which is a Lasl signal synthase. As the population of the bacteria increases, $\mathrm{AHL}$ accumulates and activates the transcriptional regulator LasR. LasR activation upregulates proteases and biofilm formation directly. LasR has two independently folded domains. The binding of its natural inducer, OdDHL ( $\mathrm{N}$-(3-oxododecanoyl) -L-homoserine lactone), stabilizes the monomeric protein and activates dimerization of the two domains [13,14]. The resulting ligand bound Las $R$ homodimer binds to target promotor region and thus activates transcription of the virulence factors. Therefore, ligands that inhibit the binding of the natural inducer, OdDHL, to LasR competitively inhibit the quorum sensing system [15]. The binding ability of ligands to LasR can be demonstrated by using molecular docking. Previous studies have demonstrated that this system can be suppressed by EOs [16-18]. Although Niaouli EOs obtained from Melaleuca species have been shown to be effective against pathogenic microorganisms resistant to antibiotics on the skin surface and oral cavity, its activity on biofilm formation of $P$. aeruginosa has not been determined [19]. In this study, the effect of Niaouli EO on biofilm inhibition was investigated. In addition, its mechanism of action was investigated through molecular docking. The effect of Niaouli EO on the viability of fibroblast cell lines was also determined.

\section{MATERIAL AND METHODS}

\section{Gas Chromatography Mass Spectrometry (GC-MS) Analysis}

Shimadzu GC-MS QP 5050 (Kyoto, Japan) gas chromatograph-mass spectrometer system was used for analysis of Niaouli EO that is commercially available (Botalife, Isparta; Turkey). Separations were carried out by a CP WAX 52 CB capillary column $(50 \mathrm{~m} \times 0.32 \mathrm{~mm}$ ID, df: $1.2 \mu \mathrm{m})$ purchased from Varian. Helium $(99.999 \%)$ was used as carrier gas at a constant head pressure of 10 p.s.i ( 1 p.s.i $=6894.76 \mathrm{~Pa}) .1 \mu \mathrm{L}$ of injection volume was used. The GC oven was programmed as follows: the initial column temperature was $60^{\circ} \mathrm{C}$; the column was heated to $220^{\circ} \mathrm{C}$ at a rate of $2^{\circ} \mathrm{C} \mathrm{min}-1$ and held at $220^{\circ} \mathrm{C}$ for $20 \mathrm{~min}$. The GC-MS interface and injector were kept at 250 and $240^{\circ} \mathrm{C}$, respectively. The mass spectrometer was run in the electron impact mode at $70 \mathrm{eV}$.

\section{Biofilm Assay}

Spectrophotometric microplate method was used for biofilm testing. Niaouli EO was dissolved in dimethylsulphoxide (DMSO). Niaouli oil at $450 \mu \mathrm{g} / \mathrm{mL}$ and OD at $600 \mathrm{~nm}$ of $0.02 P$. aeruginosa PAO1 culture were added to the wells containing Luria-Bertani broth (LB) medium. Following $48 \mathrm{~h}$ incubation at $37^{\circ} \mathrm{C}$, the microplates were washed with distilled water 3-5 times to remove the planktonic bacteria. The rest bacteria 
were dyed with $0.1 \%$ crystal violet. After 30 min, wells were washed 3 times with distilled water. Ethanol was added to the wells to dissolve the stained biofilm layer. At the end of $15 \mathrm{~min}$, the absorbance was measured at $570 \mathrm{~nm}$ (Biotek -Epoch 2 Microplate Spectrophotometer, Winooski, Vermont USA).

\section{Molecular Docking}

The 3D structure of LasR (PDB ID: 6D6L) was retrieved from the Protein Data Bank (PDB). The crystal structure is a homotetramer obtained from $P$. aeruginosa in complex with its ligand, TP-1 (Triphenyl-1) [20]. Molecular docking was carried out with AutoDock Vina [21]. It was performed with a chain of the protein at each time. Prior to docking, GRID map that covers the binding region and its surrounding residues were determined. The number of points in each dimension and the center of the GRID box were recorded. The spacing between GRID points was used in the default form $(0.375 \AA)$. For the preparation of the target, polar hydrogens were added and Gasteiger charges were assigned. For the preparation of the ligands, energy minimization was undertaken, polar hydrogens were added and Gasteiger charges were assigned. After assigning the receptor, the ligand and the size as well as the center of the GRID map, the command prompt of AutoDock Vina was run [21]. The results were visualized by using Discovery Studio. Furthermore, high quality 3D images of the interactions were generated by using PyMol.

\section{Fibroblast Cell Culture and Cell Viability}

Fibroblast cells (L929) were grown in DMEM medium containing $10 \%$ fetal bovine serum. Cells grown in $75 \mathrm{~cm}^{2}$ flasks were removed from the flask surface with $0.05 \%$ trypsin / EDTA solution. Cells were seeded in 96-well plates $\left(2 \times 10^{4}\right.$ cells/well) 24 hours prior to application of Niaouli EO. After treatment with 100, 210, 430 and $650 \mu \mathrm{g} / \mathrm{mL}$ Niaouli EO dissolved in DMSO, cell culture plates were incubated for 24,48 and $72 \mathrm{~h}$ at $37^{\circ} \mathrm{C}$. Niaouli EO was dissolved in DMSO to prepare stock solutions that were stored $-20^{\circ} \mathrm{C}$ and diluted in complete growth medium to appropriate concentrations while keeping final DMSO concentration below $1 \%$. Effect of Niaouli EO on cell viability was determined with a procedure based on mitochondrial reductase activity of viable cells using 3-(4,5-Dimethylthiazol-2-yl)-2,5-Diphenyltetrazolium Bromide (MTT) (SigmaAldrich, Germany). Cells were incubated in medium containing MTT for $3 \mathrm{~h}$. After incubation period, $100 \mu \mathrm{L}$ DMSO was added to solve formazan crystals. Optical density was measured at $570 \mathrm{~nm}$ (reference wavelength $750 \mathrm{~nm}$ ) using an automated microplate reader. The percent of cell viability was determined by the following equation.

$$
\% \text { viability }=(\mathrm{OD} \text { treated cells } / \mathrm{OD} \text { control cells }) \times 100[22]
$$

\section{Statistical Analysis}

The obtained data were compared using One-Way Analysis of Variance (ANOVA). Results were considered statistically significant $(p<0.05)$.

\section{RESULTS}

\section{Gas Chromatography Mass Spectrometry (GC-MS) Analysis}

As a result of GC-MS analysis, it was determined that 1,8-cineole (58.53\%), also known as eucalyptol, has the highest mass volume among the defined substances in Niaouli EO. Eucalyptol, characterized by strong odor, is the most well-known component of cyclic esters. After eucalyptol, $\alpha$-pinene was detected at a rate of $8.73 \%, \alpha$-terpineol and ledene were detected at a rate of $7.97 \%$ and $6.55 \%$, respectively. Other ingredients above $1 \%$ are $2.66 \% \beta$-pinene, $2.52 \%$ nerolidol, $1.98 \%$ caryophyllene, $1.71 \% \beta$-terpinyl acetate, $1.40 \%$ benzene, methyl (1-methylethyl) - (CAS) cymol and $1.07 \% \gamma$-terpinene (Table 1 and Figure 1 ).

\section{Biofilm Inhibition}

$P$. aeruginosa PAO1 was grown in the presence of different concentrations of Niaouli $\mathrm{EO}$ and the inhibition effect was detected at $450 \mu \mathrm{g} / \mathrm{mL}$. The inhibition effect of Niaouli EO on the biofilm of $P$. aeruginosa PAO1 was determined as $71 \%$ at the applied concentration and this result was found to be statistically significant $(p<0.05)$ (Figure 2). 
Table 1. GC-MS analysis of Niaouli EO \% of major components and their retention times.

\begin{tabular}{|c|c|c|c|c|}
\hline & Name of compound & $\mathbf{R I}$ & Rt (min) & Area\% \\
\hline 1 & $\alpha$-Pinene & 936 & 6.741 & 8.73 \\
\hline 2 & Camphene & 954 & 7.285 & 0.10 \\
\hline 3 & Benzaldehyde & 962 & 7.665 & 0.20 \\
\hline 4 & $\beta$-Pinene & 978 & 8.342 & 2.66 \\
\hline 5 & 6-Methyl-5-hepten-2-one & 979 & 8.575 & 0.01 \\
\hline 6 & $\beta$-Myrcene & 991 & 8.785 & 1.01 \\
\hline 7 & * & & 9.436 & 0.06 \\
\hline 8 & $\alpha$-Phellandrene & 1002 & 9.535 & 0.08 \\
\hline 9 & $\alpha$-Terpinene & 1013 & 9.685 & 0.01 \\
\hline 10 & $\beta$-o-Cymenene & 1029 & 10.037 & 0.27 \\
\hline 11 & Benzene, methyl(1-methylethyl)- (CAS) Cymol & & 10.447 & 1.40 \\
\hline 12 & 1,8-Cineole & 1034 & 11.019 & 58.53 \\
\hline 13 & * & & 11.480 & 0.03 \\
\hline 14 & $y$-Terpinene & 1062 & 12.073 & 1.07 \\
\hline 15 & $\alpha$-Terpinolene & 1089 & 13.515 & 0.56 \\
\hline 16 & 1-Methyl-4-isopropenylbenzene & & 13.740 & 0.04 \\
\hline 17 & Methyl benzoate & & 13.953 & 0.05 \\
\hline 18 & Linalool & 1097 & 14.354 & 0.19 \\
\hline 19 & * & & 15.394 & 0.04 \\
\hline 20 & trans-Pinocarveol & 1126 & 16.651 & 0.02 \\
\hline 21 & Isopulegol & 1132 & 17.156 & 0.06 \\
\hline 22 & p-Menth-1-en-8-ol & 1176 & 18.499 & 0.20 \\
\hline 23 & 2-Cyclohexen-1-ol, 2-methyl-5-(1-methylethenyl)- & 1179 & 19.030 & 0.03 \\
\hline 24 & Terpinen-4-ol & 1186 & 9.152 & 0.84 \\
\hline 25 & $\alpha$-Terpineol & 1196 & 20.236 & 7.97 \\
\hline 26 & * & & 27.771 & 0.03 \\
\hline 27 & * & & 28.380 & 0.01 \\
\hline 28 & $\alpha$-Terpinyl acetate & 1335 & 29.977 & 1.71 \\
\hline 29 & $\alpha$-Ylangene & 1376 & 31.731 & 0.10 \\
\hline 30 & $\alpha$-Gurjunene & 1413 & 33.720 & 0.14 \\
\hline 31 & Caryophyllene & 1419 & 34.476 & 1.98 \\
\hline 32 & Aromadendrene & 1423 & 35.630 & 0.04 \\
\hline 33 & $\alpha$-Humulene & 1458 & 36.695 & 0.34 \\
\hline 34 & * & & 36.982 & 0.49 \\
\hline 35 & Viridiflorene & 1491 & 39.020 & 0.93 \\
\hline 36 & $\alpha$-selinene & 1494 & 39.272 & 0.20 \\
\hline 37 & $\alpha$-Muurolene <alpha-> & 1496 & 39.532 & 0.05 \\
\hline 38 & Cadinene <gamma-> & 1507 & 40.362 & 0.20 \\
\hline 39 & $\Delta$-Cadinene & 1529 & 40.760 & 0.20 \\
\hline 40 & * & & 41.800 & 0.02 \\
\hline 41 & Nerolidol & 1562 & 43.590 & 2.52 \\
\hline 42 & Caryophyllene oxide & 1578 & 44.421 & 0.29 \\
\hline 43 & * & & 44.713 & 0.05 \\
\hline \multirow[t]{2}{*}{44} & Ledene & & 45.311 & 6.55 \\
\hline & & & & 100 \\
\hline
\end{tabular}

RI:retention indices calculated for CP-Wax 52 CB in GC-MS, * unidentifed 


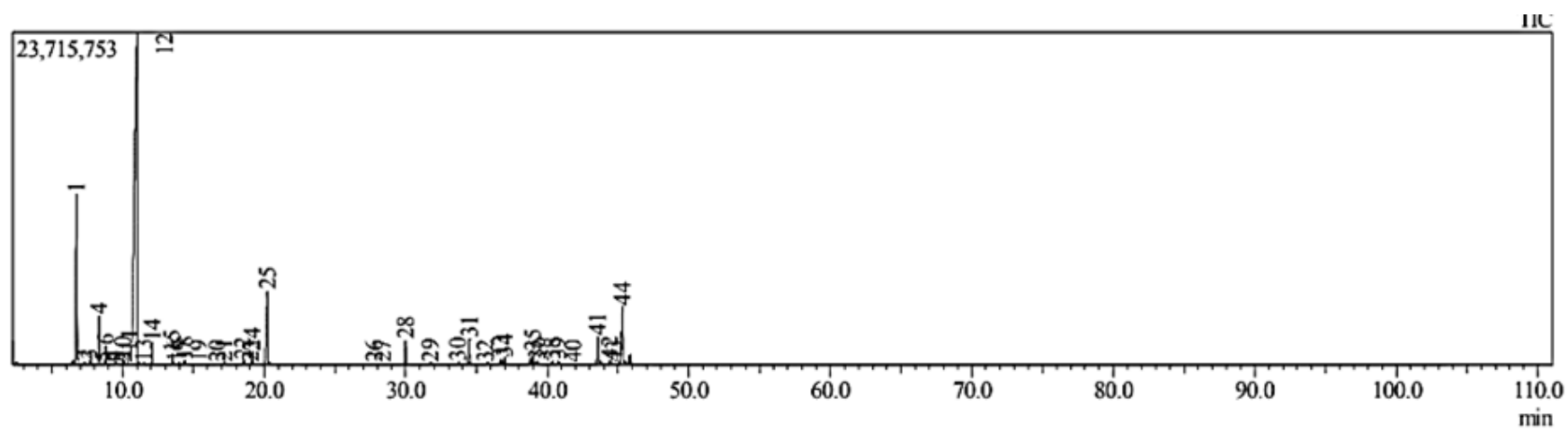

Figure 1. GC/MS chromatogram for the main compounds identified in Niaouli EO.

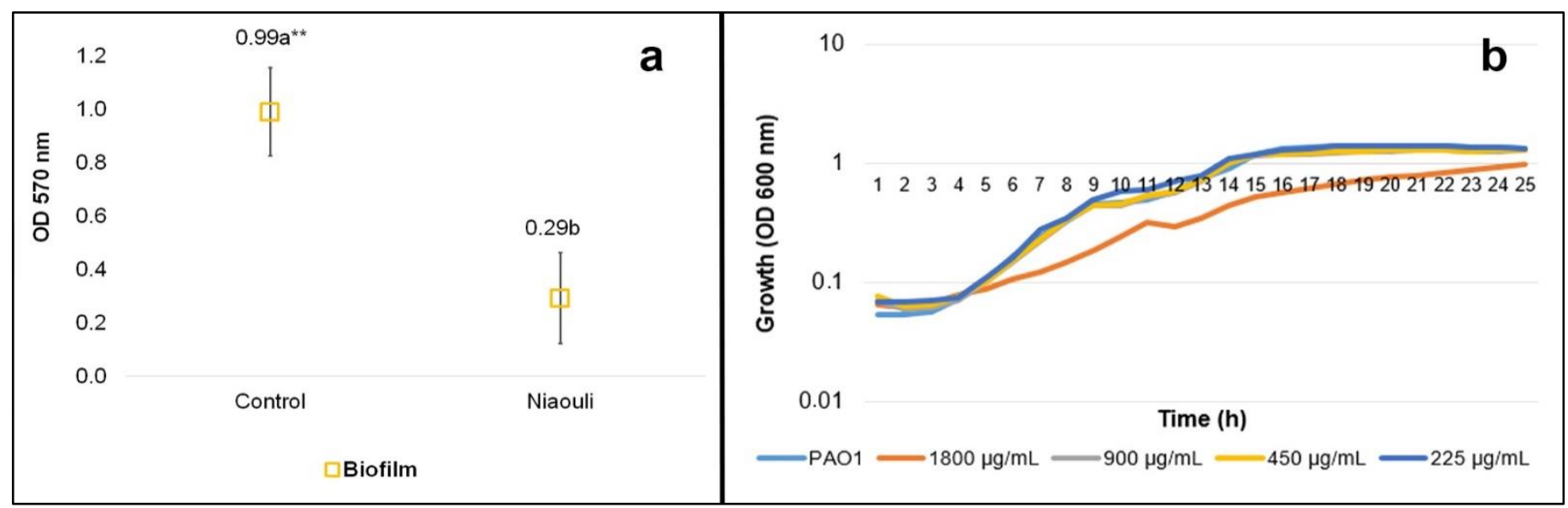

Figure 2. a) Inhibitory effect of Niaouli EO on biofilm formation in PAO1. b) Effect of Niaouli EO on PAO1 growth ( \pm SD). **Differences between mean values followed by different letters of plant extracts are statistically significant at $p<0.01$;

\section{Molecular Docking}

Results revealed that Niaouli EO contains molecules that act as LasR antagonists. 1,8-cineole constitutes $58.53 \%$ of the Niaouli EO. As 1,8-cineole is the major component of the oil according to GC-MS results and the LasR antagonist activity observed might be mainly due to the inhibition of LasR by this molecule. The other molecules with an abundance of above $2 \%$ were pinene, $\alpha$-terpineol, nerolidol and ledene. The contribution of these molecules for the inhibition of LasR was also investigated. In the molecular docking study, these possibilities were explored. 1,8-cineole, $\alpha$-pinene, $\alpha$ terpineol, nerolidol, ledene and the bound ligand TP-1 were docked against the binding region of the LasR protein using AutoDock Vina (Figure 3). Molecular docking results were also compared with the interaction of LasR with its natural ligand, OdDHL. In each case, results with the best binding energy and RMSD values were used for further investigations. All the chains of the homotetramer protein showed similar interactions as expected. Here the docking results of the $\mathrm{A}$ chain with OdDHL, TP-1, 1,8-cineole, $\alpha$-pinene, $\alpha$-terpineol, nerolidol and ledene are presented (Table 2, Figure 3). The binding energy of OdDHL, TP-1 and 1,8-cineole with the protein was found to be $-8.8 \mathrm{kcal} / \mathrm{mol},-14.0 \mathrm{kcal} / \mathrm{mol}$ and -5.7 $\mathrm{kcal} / \mathrm{mol}$, respectively. 
Table 2. Comparison of the interactions of OdDHL, TP-1, 1,8-cineole and other ligands with LasR

\begin{tabular}{|c|c|c|c|c|c|}
\hline \multirow{3}{*}{ Ligands } & \multicolumn{5}{|l|}{ Binding } \\
\hline & \multirow{2}{*}{$\begin{array}{l}\text { Energy } \\
(\mathrm{kcal} / \mathrm{mol})\end{array}$} & \multirow{2}{*}{$\begin{array}{l}\text { Hydrogen } \\
\text { Bonds }\end{array}$} & \multicolumn{3}{|c|}{ Other Amino Acid Interactions } \\
\hline & & & $\pi-\pi$ & alkyl/m-alkyl & $\pi-\sigma$ \\
\hline OdDHL & -8.8 & Thr75, Ser129 & - & $\begin{array}{l}\text { Tyr56, Tyr64, Trp88, Phe101, } \\
\text { Phe102, Ala105, Leu110 }\end{array}$ & - \\
\hline TP-1 & -14.0 & Trp60, Ser129 & $\begin{array}{l}\text { Tyr64, } \\
\text { Trp88, } \\
\text { Phe101 }\end{array}$ & $\begin{array}{l}\text { Leu36, Val76, Cys79, Ala105, } \\
\text { Leu125, Ala127 }\end{array}$ & - \\
\hline 1,8-Cineole & -5.7 & Tyr64 & - & Leu36 & Tyr64 \\
\hline$\alpha$-pinene & -5.6 & - & - & $\begin{array}{l}\text { Leu36, Tyr47, lle52, Tyr64, Ala70, } \\
\text { Val76 }\end{array}$ & - \\
\hline$\alpha$-terpineol & -6.0 & - & - & Trp88, Phe101, Phe102, Ala105 & - \\
\hline Nerolidol & -6.5 & - & - & Leu36, Tyr56, Phe101, Ala105 & Tyr64, Trp88 (2) \\
\hline Ledene & -7.0 & - & - & Leu36, Ile52, Tyr64 & - \\
\hline
\end{tabular}




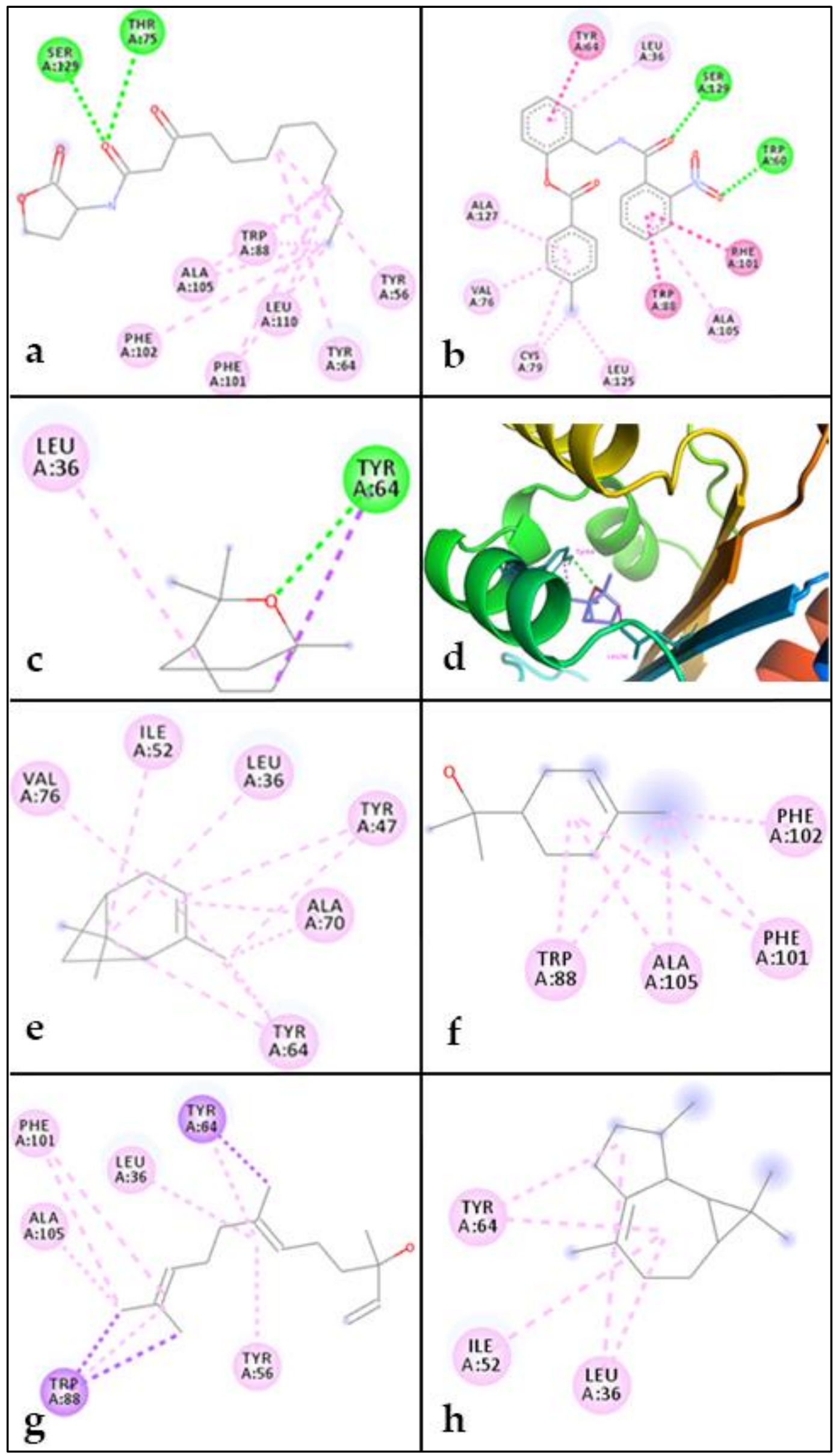

Figure 3. The interactions of docked molecules with LasR. a) OdDHL, b) TP-1, c) 1,8-cineole, d) 1,8-cineole 3D binding, e) $\alpha$-pinene, f) $\alpha$-terpineol, g) nerolidol and h) ledene . 


\section{Effects of Niaouli EO on Fibroblast Cell Viability}

As seen in Figure 4, all applications of Niaouli EO had significant inhibitory activity on fibroblasts viability for all hours $(p<0.05)$ when compared to control groups. Two of the higher concentrations $(430 \mu \mathrm{g} / \mathrm{mL}$ and $650 \mu \mathrm{g} / \mathrm{mL}$ ) reduced cell viability much more, compared to the other lower concentrations (100 and 210 $\mu \mathrm{g} / \mathrm{mL}$ ). Although these two higher concentrations were not statistically different among themselves, they differ significantly from the control and lower concentrations $(p<0.05)$. $I_{50}$ values were calculated $425 \pm 2$ $\mu \mathrm{g} / \mathrm{mL}$ for $24 \mathrm{~h}, 300 \pm 1 \mu \mathrm{g} / \mathrm{mL}$ for $48 \mathrm{~h}$ and $335 \pm 1 \mu \mathrm{g} / \mathrm{mL}$ for $72 \mathrm{~h}$.

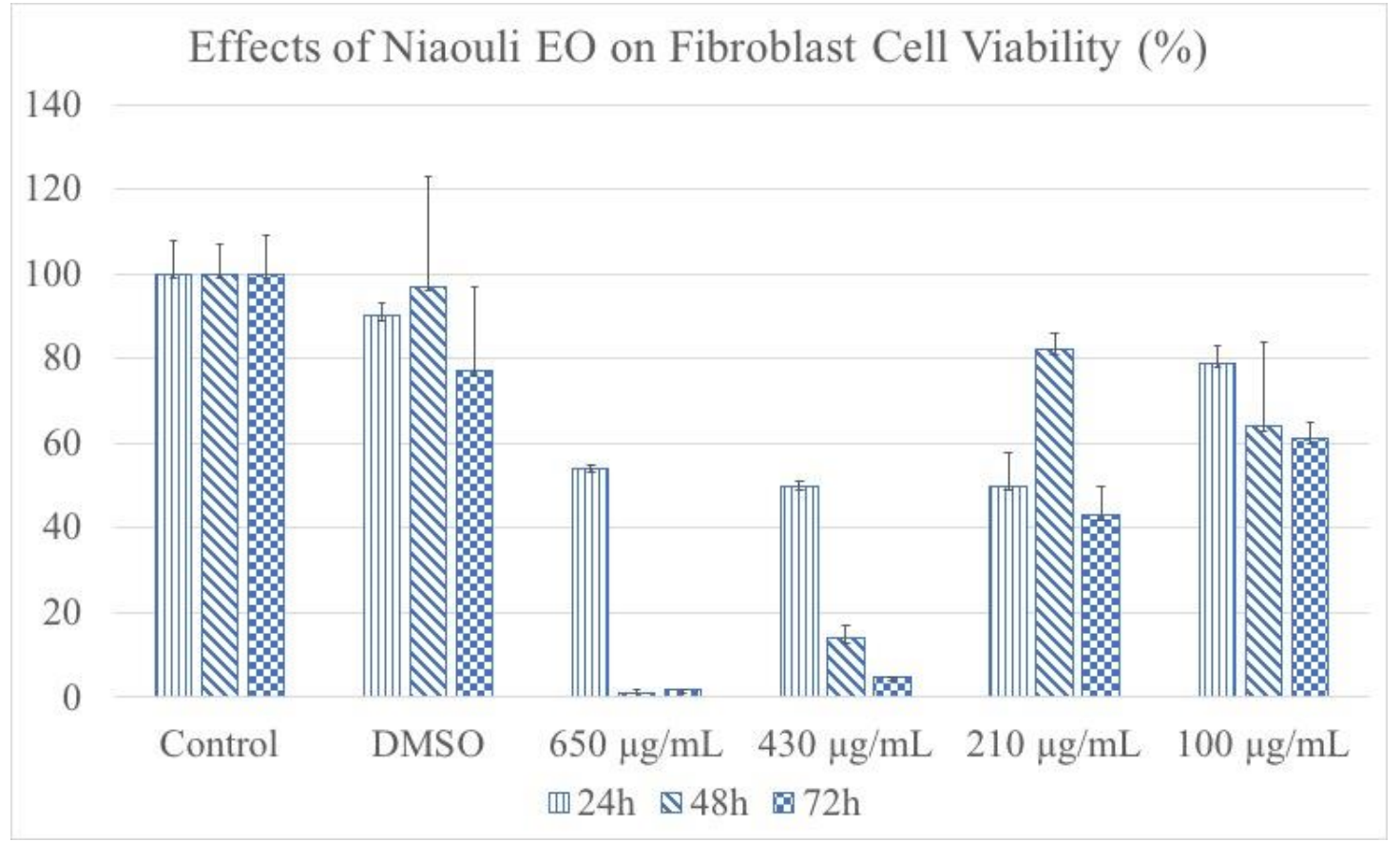

Figure 4. Cytotoxicity of Niaouli EO on fibroblast cells for 24,48 and $72 \mathrm{~h}$. Results are expressed as \% of control and represent the mean $\pm S D$ of at least two experiments

\section{DISCUSSION}

EOs and their components are important compounds for biomedical or pharmaceutical purposes due to their medicinal properties. Moreover, due to their antibacterial properties, EOs are used in various commercial products such as dental root canal sealers. They have ability to damage cell walls and enzymatic activities of pathogenic microorganisms [23]. Being an opportunistic pathogen, $P$. aeruginosa shows high tolerance to antibiotics because of its biofilm-forming ability, and it has been reported that biofilm-associated cells are more active in efflux pump expression than planktonic cells [11,12]. Unfortunately, there is currently no treatment strategy that can prevent biofilm formation [24]. Biofilm formation controlled by quorum sensing system and AHLs in Gram-negative bacteria, can be prevented by the inhibition of this system in various ways such as enzymatic degradation of signal molecules and antagonists of signal molecules [25]. For example, it has been reported that meta-bromo-thiolactone inhibits biofilm formation in $P$. aeruginosa, causing a decrease of infection [25, 26]. In addition to synthetic molecules, studies have reported that polyphenols, flavonoids, flavanones and many other phytochemicals suppress the quorum sensing system of many different bacterial species $[16,18]$. There are many studies conducted with plant essential oils and active ingredients such as 1,8-cineole, an inhibition was found in the range of $77.46 \pm 1.91$ to $90.81 \pm 4.05 \%$ on biofilm formation in clinical Methicillin-resistant $S$. aureus (MRSA) strains [17]. In our study, Niaouli EO contains high content of 1,8 -cineole $(58,53 \%)$, also had inhibition biofilm formation consistent with study of Ramanoelina and coauthors [28]. However, in the literature reviews so far, there is no study investigating the effect of Niaouli EO on biofilm formation in P. aeruginosa PAO1. This is the first study to show that Niaouli EO inhibits the formation of biofilm and to be verified by the molecular docking study.

This study revealed that 1,8-cineole is the major component of Niaouli EO with $58.53 \%$. Pinene, $\alpha$ terpineol, nerolidol and ledene were also found to have concentrations above $2 \%$. Since several phytochemicals in an extract might act together to bring a pharmacological effect, the contribution of the components with relatively higher abundance was investigated computationally [28]. The computational 
analysis exhibited that the phytochemical components of Niaouli EO might inhibit the QS system by interfering with the binding of the natural ligand with LasR. The interaction was achieved mainly through the major component, 1,8-cineole. Furthermore, $\alpha$-pinene, $\alpha$-terpineol, nerolidol and ledene were found to have contributions for the interaction detected. In a previous experimental work in the L3 loop of LasR, which likely have a functional role, Leu40, Val76 and Leu125 were found to be important for the binding of a ligand [21]. Similarly, in this docking work interactions at Val76 and Leu125 were detected. In another experimental study, the natural agonist of LasR, OdDHL, was also found to have hydrogen bonds at Trp60 and Ser129 as in TP1 [29]. These studies supported the docking results reported here. Hence, the result obtained from the redocking of the bound ligand, TP-1, validated the docking results. Furthermore, the interactions at Leu36 and Tyr64 were observed in TP-1 and 1,8-cineole. This showed the similarity between the interactions of the two molecules. TP-1 is a potent LasR agonist and there are TP-derived compounds that are antagonists [15]. Molecular docking results revealed that 1,8-cineole has similar binding interactions to TP-1. In addition to this, almost all the binding interactions of the natural ligand, OdDHL, with LasR were satisfied by 1,8-cineole and the other phytochemicals investigated. It is important to note that the common conventional hydrogen bond was achieved by 1,8-cineole. Most of the common hydrophobic interactions with the natural ligand were achieved through the rest phytochemicals ( $\alpha$-pinene, $\alpha$-terpineol, nerolidol and ledene). This suggests that 1,8-cineole and the other phytochemical components might be an antagonist to LasR by inhibiting the binding of OdDHL and the agonist, TP-1, in the binding region. Thus, 1,8-cineole with the other components of Niaouli EO can reduce the virulence factors by inhibiting the QS system.

We also evaluated the effect on fibroblast cell viability in order to analyze the cytotoxicity of Niaouli EO. $\mathrm{IC}_{50}$ values were determined above $100 \mu \mathrm{g} / \mathrm{mL}$ for all applied hours as seen from the result part. According to The National Cancer Institute of USA (US-NCI), $I_{50}$ value of less than $100 \mu \mathrm{g} / \mathrm{mL}$ should be assessed cytotoxic [2]. Therefore, Niaouli can be considered non-toxic on fibroblast cells, because $\mathrm{IC}_{50}$ value was $335 \pm 1 \mu \mathrm{g} / \mathrm{mL}$ for $72 \mathrm{~h}$. In parallel with our findings, it was shown that Tea tree oil (TTO) obtained from $M$. alternifolia was significantly less efficacious against non-tumor fibroblast cells compared to tumour cells [31]. Meanwhile, Liu and coauthors [32] have reported that TTO shows strong in vitro cytotoxicity towards human lung cancer cell line, human breast cancer cell line and human prostate cancer cell line. Cytotoxicity of $M$. alternifolia oil and its main monoterpenes also were investigated on another cell lines such as HepG2, HeLa, MOLT-4, K-562 and CTVR-1 cells and cytotoxic activity was found as 1,8-cineole, terpinen- 4-ol, tea tree oil, $\alpha$-terpineol [33]. Based on our results, we observed that Niaouli had no adverse effect on cell viability of fibroblasts if high doses of Niaouli EO were not used.

In conclusion, Niaouli EO has no toxic effects in fibroblast cells, but it has inhibitory activity on biofilm formation of PAO1 and it can be a potential quorum sensing inhibitor. These biological activities make Niaouli EO a promising agent against pathogenic microorganisms which can form biofilm. It is obvious that further studies are needed to evaluate the effectiveness of Niaouli in vivo for dermatological applications.

Funding: This research received no external funding.

Acknowledgments: In this section you can acknowledge any support given which is not covered by the author contribution or funding sections. This may include administrative and technical support, or donations in kind (e.g., materials used for experiments).

Conflicts of Interest: The authors declare no conflict of interest

\section{REFERENCES}

1. Kumar D, Sukapaka M, Babu GDK, Padwad Y. Chemical composition and in vitro cytotoxicity of essential oils from leaves and flowers of Callistemon citrinus from Western Himalayas. PLoS ONE. 2015;10(8):e0133823. https://doi.org/10.1371/journal.pone.0133823.

2. Montero-Villegas S, Crespo R, Rodenak-Kladniew B, Agustina Castro M, Galle M, Cicció JF, et al. Effects of essential oils from four Lippia alba chemotypes in human liver and lung cancer cell lines. J. Essent. Oil Res. 2018;30:167-181. doi: 10.1080/10412905.2018.1431966.

3. Yongkyu L. Cytotoxicity evaluation of essential oil and its component from Zingiber officinale Roscoe. Toxicol. Res. 2016;32(3):225-230. doi:10.5487/TR.2016.32.3.225

4. Viana MDM, Neto GJS, de Lima AA, Leite AB, Souza IT, Santana AEG, et al. Citrus limon (L.) Burm f. Essential oil has anxiolytic and sedative properties by modulating GABAA-receptors. Braz. Arch. Biol. Technol. 2020;Vol.63: e20200206.

5. Sobrinho ACN, Morais SM, Souza EB, Albuquerque MRJR, Santos HS, Cavalcante CSP, et al. Antifungal and antioxidant activities of Vernonia Chalybaea Mart. ex DC. essential oil and their major constituent $\beta$-caryophyllene. Braz. Arch. Biol. Technol. 2020;63: e20190177 
6. Nam S-Y, Chang M-H, Do J-S, Seo H-J, Oh HK. Essential oil of Niaouli preferentially potentiates antigen-specific cellular immunity and cytokine production by macrophages. Immunopharmacol. Immunotoxicol. 2008;30:3,459-474.

7. Carson CF, Hammer KA, Riley TV. Melaleuca alternifolia (Tea Tree) Oil: a review of antimicrobial and other medicinal properties. Clin. Microbiol. Rev. 2006; 50-62.

8. Acha E, Ahounou Aikpe JF, Adovelande J, Assogba MF, Agossou G, Sezan A, et al. Anti-inflammatory properties of Melaleuca quinquenervia (Cav.) ST Blake Myrtaceae (Niaouli) leaves' essential oil. Int. J. Curr. Res. Chem. Pharm. Sci. 2019;6(1): 30-40.

9. Ceylan O, Ugur A. Chemical composition and anti-biofilm activity of Thymus sipyleus BOISS. subsp. sipyleus BOISS. var. davisianus RONNIGER essential oil. Arch Pharm Res. 2015 Jun;38(6):957-65. doi: 10.1007/s12272014-0516-0. Epub 2014 Nov 11. PMID: 25385321.

10. Garrett, T.R., M. Bhakoo, and Z. Zhang. 2008. Bacterial adhesion and biofilms on surfaces. Prog. Nat. Sci. 18: 1049-1056.

11. Zhang L, Mah TF. Involvement of a novel efflux system in biofilm-specific resistance to antibiotics. J Bacteriol. 2008;190:4447-4452. https://doi.org/10.1128/JB.01655-07.

12. Algburi A, Comito N, Kashtanov D, Dicks LMT, Chikindas ML. Control of biofilm formation: antibiotics and beyond. Applied and Environmental Microbiology. 2017;83(3): e02508-16.

13. Rajesh PS, Rai VR. Inhibition of QS-regulated virulence factors in Pseudomonas aeruginosa PAO1 and Pectobacterium carotovorum by AHL-lactonase of endophytic bacterium Bacillus cereus VT96. Biocatal. Agric. Biotechnol. 2016;7:154-163. https://doi. org/10.1016/j.bcab.2016.06.003

14. Paluch E, Rewak-Soroczyńska J, Jędrusik I, Mazurkiewic E, Jermakow K. Prevention of biofilm formation by quorum quenching. Appl. Microbiol. Biotechnol. 2020;104:1871-81.

15. Bottomley MJ, Muraglia E, Bazzo R, Carfi A. Molecular insights into quorum sensing in the human pathogen Pseudomonas aeruginosa from the structure of the virulence regulator LasR bound to its autoinducer. J. Biol. Chem. 2007;282,13592-600.

16. Kalia VC. Quorum sensing inhibitors: an overview. Biotechnol. Adv. 2013;31,:224-45. doi: 10.1016/j.biotechadv.2012.10.00

17. Merghnia A, Noumia E, Haddeda O, Dridia N, Panward H, Ceylan O, et al. Assessment of the antibiofilm and antiquorum sensing activities of Eucalyptus globulus essential oil and its main component 1,8-cineole against methicillin-resistant Staphylococcus aureus strains. Microbial Pathogenesis. 2018;118:74-80.

18. Qvortrup K, Hultqvist LD, Nilsson M, Jakobsen TH, Jansen CU, Uhd J, et al. Small molecule anti-biofilm agents developed on the basis of mechanistic understanding of biofilm formation. Front. Chem. 2019;7:742. doi: 10.3389/fchem.2019.00742

19. Oliveira TR, Laerte Teixeira A, Barbosa JP, Busato de Feiria SN, Boni GC, Maia F, et al. Melaleuca spp Essential Oil And Its Medical Applicability. A Brief Review. Braz. J. Nat. Sci. 2020, 3(1): 249-58.

20. O'Reilly MC, Dong SH, Rossi FM, Karlen KM, Kumar RS, Nair SK. Structural and biochemical studies of non-native agonists of the LasR Quorum-Sensing Receptor reveal an L3 Loop "Out" conformation for LasR. Cell Chem Biol. 2018, 25(9):1128-39.

21. Trott O, Olson A. Autodock vina: improving the speed and accuracy of docking. J Comput Chem. 2010;31(2):45561.

22. Hosseinzadeh N, Shomali T, Hosseinzadeh S, Raouf Fard F, Jalaei J, Fazeli M. Cytotoxic activity of Ferula persica gum essential oil on murine colon carcinoma (CT26) and Vero cell lines. J. Essent. Oil Res. 2020;32:(2)169-177. DOI: $10.1080 / 10412905.2020 .1729880$.

23. Baptista-Silva S, Borges S, Ramos OL, Pintado M, Sarmento B. The progress of essential oils as potential therapeutic agents: Review. J. Essent. Oil Res. 2020;279-295. 10.1080/10412905.2020.1746698

24. Popova M, Gerginova D; Trusheva B, Simova S, Tamfu AN, Ceylan O, et al. A preliminary study of chemical profiles of honey, cerumen, and propolis of the african stingless bee Meliponula ferruginea. Foods 2021,10,997. https://doi.org/10.3390/ foods10050997

25. Boudiba S, Tamfu AN, Berka B, et al. Anti-Quorum Sensing and Antioxidant Activity of Essential Oils Extracted From Juniperus Species, Growing Spontaneously in Tebessa Region (East of Algeria). Natural Product Communications. June 2021. doi:10.1177/1934578X211024039

26. O'Loughlin CT, Miller LC, Siryaporn A, Drescher K, Semmelhack MF, Bassler BL. A quorum-sensing inhibitor blocks Pseudomonas aeruginosa virulence and biofilm formation. Proceedings of the National Academy of Sciences of the United States of America. 2013;110(44): 17981-17986.

27. Jiang Q, Chen J, Yang C, Yin Y, Yao K. Quorum Sensing: a prospective therapeutic target for bacterial diseases. BioMed Research International. 2019;15. https://doi.org/10.1155/2019/2015978 
28. Ramanoelina PAR, Bianchini JP, Gaydou EM. Main industrial Niaouli (Melaleuca quinquenervia) oil chemotype productions from Madagascar, J. Essent. Oil Res. 2008;20(3):261-266.

29. Assis DB, Neto HCA, Fonseća DV, Andrade HHN, Braga RM, Badr N, Maia, MS, Castro RD, Scotti L, Scotti MT, Almeida RNB. Antinociceptive activity of chemical components of essential oils that involves docking studies: A review. Front. Pharmacol. 2020;11:1-19. https://doi.org/10.3389/fphar.2020.00777

30. Galloway WRJD, Hodgkinson JT, Bowden SD, Welch M, Spring DR. Quorum sensing in gram-negative bacteria: Small-molecule modulation of AHL and Al-2 quorum sensing pathways. Chem Rev. 2011;111(1): 28-67.

31. Liu X, Zu Y, Fu Y, Yao L, Gu C, Wang W, et al. Antimicrobial activity and cytotoxicity towards cancer cells of Melaleuca alternifolia (tea tree) oil. Eur. Food Res. Technol. 2009;229(2): 247-53. doi:10.1007/s00217-009-10575

32. Greay SJ, Ireland DJ, Kissick HT, Levy A, Beilharz MW, Riley TV, et al. Induction of necrosis and cell cycle arrest in murine cancer cell lines by Melaleuca alternifolia (tea tree) oil and terpinen-4-ol. Cancer Chemother. Pharmacol. 2009;65(5): 877-88.

33. Hayes AJ, Leach DN, Markham JL, Markovic B. In vitro Cytotoxicity of Australian Tea Tree Oil using Human Cell Lines, Journal of Essential Oil Research, 1997;9:5, 575-582.

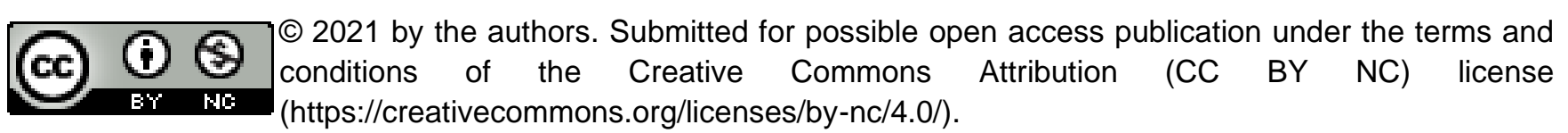

